\title{
$\bullet$ \\ IJCRR \\ Section: Healthcare \\ Determination of Gamma-Glutamyltransferase in Type 2 Diabetes Mellitus and its Relation with Disease Treatment
}

ISI Impact Factor

(2019-20): 1.628

IC Value (2019): 90.81

$\operatorname{SJIF}(2020)=7.893$

(c) (1) (8)

Copyright@IJCRR

\author{
Arvind Kumar Kushwaha ${ }^{1}$, Karanpreet Bhutani2* , Suvarna Prasad ${ }^{3}$, \\ Punam Rani ${ }^{4}$
}

'M.Sc. Med. Biochemistry, MMIMSR, MMDU, Mullana; 'Assistant Professor, Department of Biochemistry, MMIMSR, MMDU, Mullana; 3Professor \& Head, Department of Biochemistry, MMIMSR, MMDU, Mullana; ${ }^{4}$ M.Sc. Med. Biochemistry, MMIMSR, MMDU, Mullana.

\section{ABSTRACT}

Introduction: Diabetes Mellitus is one of the most common metabolic disorders. Various pathogenic processes are involved in the growth of diabetes; insulin deficiency,insulin resistance. Oxidative stress can also play a role in the cause and pathophysiology of diabetes.

Gamma-glutamyltransferase (GGT) has a pivotal role in the maintenance of intracellular antioxidant defences through its mediation of extracellular glutathione transport into most types of cells. Gamma-glutamyltransferase enzymatic activity may also be indicative of an early risk of inflammation.

Aims and Objectives: To study the levels of Gamma-glutamyltransferase, FBS, HbA1c in type 2 diabetes patients. To find out correlations if any between the Gamma-glutamyltransferase Level with FBS, HbA1c. To evaluate GGT levels in controlled and uncontrolled cases of type 2 diabetic patients.

Material and Methods: In this study, 100 study subjects with age above 40 years were divided into two groups - 50 patients having type 2 DM (the study group) and 50 healthy individuals (the control group). From the venous blood, serum gammaglutamyltransferase was measured using a semi-auto analyser (ErbaChem 5 plus) using commercially available kits.FBS was measured by Erba XL (EM 360), HbA1c was measured by SD Biosensor. Ethical clearance was taken vide letter number 1397.

Results: The mean value of GGT in the study group was 68.34 and in the control group it was 31.22 (p-value <0.0001). There is a significant difference between serum gamma-glutamyltransferase values of the control group and the study group.

Conclusion: There were increased levels of serum gamma-glutamyltransferase in patients with type 2 Diabetes Mellitus.

Key Words: Type 2 Diabetes mellitus, Gamma-glutamyltransferase, FBS, HbA1c, Insulin resistance, Oxidative stress

\section{INTRODUCTION}

Diabetes Mellitus (DM) is a group of metabolic diseases characterized by the increased level of blood glucose resulting from a deficiency in insulin secretion, dysfunction of insulin action or both. Diabetes Mellitus is one of the most common metabolic disorder, there are approximately 200 million Diabetics in the world; thus creating a need to understand the aetiology of the disorder and the factors affecting its onset. Various pathogenic processes are involved in the growth of diabetes; these range from autoimmune loss of the beta cell of the pancreas with consequent insulin deficiency to abnormalities that result in resistance to insulin activity. ${ }^{1}$
The Gamma-glutamyltransferase (GGT) is an enzyme of molecular weight 68,000 Dalton found in many tissues, e.g. liver, gallbladder, spleen, pancreas and kidneys that play a fundamental role in the metabolism of glutathione as an antioxidant agent. ${ }^{2,3}$

Gamma glutamyltransferase has a pivotal role in the maintenance of intracellular antioxidant defences through its mediation of extracellular glutathione transport into most types of cells. ${ }^{4,5,6}$ Oxidative stress is associated with several pathological conditions, such as inflammation, carcinogenesis, ageing, atherosclerosis, and reperfusion injury. ${ }^{7}$ Oxidative stress can also play a role in the cause and pathophysiology of diabetes. ${ }^{8,9}$

\section{Corresponding Author:}

Dr. Karanpreet Bhutani, Assistant Professor, Department of Biochemistry, MMIMSR, MMDU, Mullana.

Phone: 9915565275; Email: karanpreet.biochem@gmail.com

ISSN: 2231-2196 (Print) ISSN: 0975-5241 (Online)

Received: 19.10.2020

Revised: 24.12 .2020

Accepted: 03.03 .2021

Published: 20.07 .2021 


\section{AIM AND OBJECTIVES}

1. To study the levels of Gamma-glutamyltransferase, FBS, HbA1c in type 2 diabetes patients.

2. To find out the correlation between the Gamma-glutamyltransferase Level with FBS, HbA1c.

3. To evaluate GGT levels in controlled and uncontrolled cases of type 2 diabetes patients.

\section{MATERIAL AND METHODS}

\section{Study area}

The present study was undertaken in the Department of Biochemistry in collaboration with the Department of Medicine, M.M Institute of Medical Sciences and Research, MMDU, Mullana, Ambala.

\section{Study design}

\section{Case-Control Study}

\section{Study period}

This study was conducted from July 2018 to June 2020 .

\section{Selection of patients}

In this study, 100 study subjects with age above 40 years were divided into two groups - 50 patients having type 2 $\mathrm{DM}$ (the study group) and 50 healthy individuals (the control group).

\section{Study population}

A detailed history regarding the present or past illness was taken, the general physical examination, local examination and the systemic examination were done as per the Performa.

\section{Inclusion criteria}

1. Subjects diagnosed with type 2 Diabetes

2. Age above 40 years

\section{Exclusion criteria}

1. Type 1 Diabetes

2. Patients less than 40 years

3. Patients suffering from chronic renal failure, on renal replacement therapy

4. Patients with a history of alcohol abuse

5. Patients with hepatocellular diseases, smoking

6. Pregnancy

\section{Collection and processing of blood sample}

$5 \mathrm{ml}$ of venous blood sample was collected from the antecubital vein of the subjects in a disposable syringe under aseptic conditions and transferred to a sterile, dry and acid-washed vial for biochemical analysis. The blood was allowed to stand for half an hour. After the clot formation, the supernatant was centrifuged to perform the GGT estimation.
$2 \mathrm{ml}$ of venous blood sample in EDTA vial was collected. The supernatant was centrifuged to perform the blood glucose and $\mathrm{HbAlc}$ estimations.

\section{Details of investigations}

Estimation of Gamma-glutamyl transferase ${ }^{10}$

Method- SZASZ method

Estimation of blood glucose by GOD-POD method $^{11}$

\section{Method-Trinder's}

\author{
Estimation of HbA1c by SD Biosensor ${ }^{12}$
}

\section{RESULTS}

The majority of subjects of the study group had serum Gamma-glutamyltransferase in the range $>52$ IU/L (78.0\%). While the control group had the majority of subjects with Serum gamma-glutamyltransferase in the range 21-52 IU/L (66.0\%).On comparing the data statistically, a highly significant difference was observed among the groups ( $\mathrm{p}$ $<0.0001)$. There was a significant difference between serum Gamma-glutamyltransferase values of the control group and the study group (p-value $<0.0001)$ (Table-1). There were 6patients in the study group who had controlled Diabetes Mellitus (HbAlc $<6.5 \%$ ), out of which 1 had Gammaglutamyltransferase $<20 \mathrm{IU} / \mathrm{L}$, another 1 patient had Gamma-glutamyltransferase between $21-52 \mathrm{IU} / \mathrm{L}$ and 4 patients had Gamma-glutamyltransferase $>52 \mathrm{IU} / \mathrm{L}$. There were 44 patients in the study group having uncontrolled Diabetes Mellitus (HbA1c >6.5\%), out of which 3 cases had Gamma-glutamyltransferase $<20$ IU/L, 23 cases had Gammaglutamyltransferase between 21-52 IU/L, and 18 cases had gamma-glutamyltransferase $>52$ IU/L (Table 2). Plasma FBS and $\mathrm{HbA} 1 \mathrm{c}$ had no significant correlation with Serum Gamma-glutamyltransferase (Table-3).

\section{DISCUSSION}

Type 2 Diabetes Mellitus is a threat to human health because of increased morbidity and mortality associated with advanced complications of this disease. Oxidative stress is a major factor, which plays an important role in the pathogenesis of type 2 Diabetes Mellitus. ${ }^{13}$

A maximum number of subjects in the study group were in the age group $51-60$ years $(40 \%)$, the maximum number of subjects in the control group were in the age group $51-60$ years $(40 \%)$. In the study group, the maximum number of patients were female (54\%), while in the control group, the maximum number of patients were males $(56 \%)$. The majority of subjects of the study group had HbAlc in the range of 
$6.5-8.5 \%$. While the control group had the majority of subjects with $\mathrm{HbA} 1 \mathrm{c}$ in the range $<6.5 \%$. On comparing the data statistically, a highly significant difference was observed among the groups $(p<0.0001)$. However, 6 subjects in the study group having $\mathrm{HbA} 1 \mathrm{c}$ below $<6.5 \%$, were controlled diabetic cases.

There were a significant correlation between serum Gamma- glutamyltransferase values of control groups and study groups ( $p$-value $<0.0001$ ). These findings were following the studies conducted by Maryam T, et al., ${ }^{14}$ Lediju O, Abidoye O, et al., ${ }^{15}$ Prasad K HL, Das S, et al., ${ }^{16}$ Raikwar Dr. V, et al., ${ }^{17}$ Maithri CM, Manoj P, et al., ${ }^{18}$ Agarawal J, et al. ${ }^{19}$ This increase in gamma-glutamyltransferase levels in patients of type 2 Diabetes Mellitus can be attributed to several possible mechanisms. Elevation of serum Gamma - glutamyltransferase could be the expression of excess deposition of fat in the liver, termed non-alcoholic fatty liver disease. Fatty liver is thought to cause hepatic insulin resistance and to contribute to the development of systemic insulin resistance and hyperinsulinemia. Gamma-glutamyltransferase could serve as a marker of insulin resistance syndrome in the pathogenesis of diabetes. Another possible mechanism is that Gammaglutamyltransferase plays an important role in antioxidant systems. Experimental studies have reported that Gammaglutamyltransferase has a central role in the maintenance of intracellular antioxidant defences transport into most types of cells. Hence, raised Gamma-glutamyltransferase concentrations could be a marker of oxidative stress, which might also play a role in the cause and development of diabetes..$^{20}$

There were 6patients in the study group of controlled Diabetes Mellitus (HbA1c $<6.5 \%$ ), out of which 1 had Gamma-glutamyltransferase $<20 \mathrm{IU} / \mathrm{L}$, another 1 patient had Gamma glutamyltransferase between 21-52 IU/L and 4 patients had Gamma-glutamyltransferase $>52$ IU/L. There were 44 cases in a study group of uncontrolled Diabetes Mellitus (HbAlc $>6.5 \%$ ) out of which 3 cases had Gamma-glutamyltransferase $<20$ IU/L, 23 cases had Gammaglutamyltransferase between 21-52 IU/L, and 18 cases had Gamma-glutamyltransferase $>52$ IU/L. Treatment of diabetes mellitus using oral hypoglycemic drugs does not seem to have a significant influence on GGT levels. Further studies may be required in this regard. Plasma FBS and HbAlc have no significant correlation with Serum Gamma-glutamyltransferase.

\section{CONCLUSION}

There were increased levels of serum Gamma-glutamyltransferase in patients with type 2 Diabetes Mellitus. Therefore, it may be useful to determine serum Gamma-glutamyltransferase as a marker of oxidative stress in type 2 Diabetes Mellitus patients and prevent the vascular and non-vascular complications of type 2DiabetesMellitus. This will help in better management of the disease.

\section{ACKNOWLEDGEMENT}

Authors acknowledge the immense help received from the authors whose articles are cited and included in references to this manuscript. The authors are also grateful to authors/editors/publishers of all those articles, journals and books from where the literature for this article has been reviewed and discussed.

\section{Source of Funding: Nil}

\section{Conflict of Interest: Nil}

\section{Authors Contribution:}

Arvind Kumar Kushwaha- collected the data and performed the analysis

Karanpreet Bhutani - drafting the article, critical revision of the paper and final approval of the version

Suvarna Prasad - Designed the analysis and checked the article layout

Punam Rani - Analysis of the collected data

\section{REFERENCES}

1. Malecki MT, Klupa T. Type 2 diabetes mellitus: from genes to disease. Pharmac Rep. 2005;57:20-32.

2. Whitfield JB. Gamma GlutamylTransferase. Crit Rev Clin Labor Sci. 2001 Jan 1;38(4):263-355.

3. Guyton AC and Hall JE. Text Book of Medical Physiology. $11^{\text {th }}$ Edition, Elsevier Saunders, Philadelphia, 2006 p. 188.

4. Kugelman A, Choy HA, Liu R, Shi MM, Gozal E. Gammaglutamyl transpeptidase is increased by oxidative stress in rat alveolar L2 epithelial cells. Am J Respir Cell Mol Biol. 1994;11:5865-92.

5. Takahashi Y, Oakes SM, Williams MC, Takahashi S, Miura T, JoyceBrady M. Nitrogen dioxide exposure activates gammaglutamyltransferase gene expression in rat lung. Toxicol Appl Pharmacol. 1997;143: 388-96

6. Karp DR, Shimooku K, Lipsky PE. The expression of gammaglutamyl transpeptidase protects Ramos B cells from oxidationinduced cell death. J Biol Chem. 2001;276:3798-3804.

7. Droge W. Free radicals in the physiological control of cell function. Physiol Rev. 2002;82:47-95.

8. Rosen P, Nawroth PP, King G, et al. The role of oxidative stress in the onset and progression of diabetes and its complications: a summary of a Congress Series sponsored by UNESCO-MCBN, the American Diabetes Association and the German Diabetes Society. Diabetes Metab Res Rev. 2001;17:189-212.

9. Vlassara H, Palace MR. Diabetes and advanced glycation end products. J Intern Med. 2002;251: 87-101

10. SZASZ G. Reaction rate method for gamma-glutamyltransferase activity in serum. Clin. Chem. 1976;22:2051-55.

11. Trinder, P. Ann. Clin. Biochem. 1969;6(24)

12. Rohlfing CL. et al. Use of HbA1c in Screening for undiagnosed Diabetes in the U.S. population. Diabetes Care. 2000;23(2):187191. 
13. Sharma R, Mahajan M. Serum gamma-glutamyltransferase and magnesium as markers of oxidative stress in type 2 diabetic patients. Int J Curr Res. 2016;8(03): 28558-62.

14. Maryam T, Hadi H, Farzad H, Yadolladh M and Fereidoun A. Association of liver enzymes with incident type 2 diabetes: A nested case-control study in an Iranian population. BMC End Dis. 2008;8:5

15. Lediju O, Oluseyi A, Zarfishan Z. et al. Serum gamma-glutamyltransferase levels in diabetes mellitus. BMC End Dis. 2017;4(9):624-625.

16. Prasad K HL, Das S. Serum gamma-glutamyltransferase and sialic acid levels in type 2 diabetic patients and its association with glycemic control. BMC End Dis. 2018;7(5):12361-12366.
17. Raikwar V, Vinod Dangi, Aprrorva S. Liver function test parameters in patients having type 2 diabetes mellitus and hypertensive diabetes. Int J Med Res. 2018;3(1):10-12.

18. Maithri CM, Manoj P, Mahadev SK, Tejaswani. Association of gamma-glutamyltransferase activity with fasting glucose among first degree relatives of type 2 diabetes patients. Int J Clin Biochem Res. 2019;6(4):458-63.

19. Aggarwal J, Singh N, Kumar M. Analysis of serum gamma-glutamyl transpeptidase level as a marker for the detection of type 2 diabetes mellitus in Okhla industrial area. Int. J. Clin Biochem Res. 2019;6(3):336-9

20. Meena SK, Meena A, Ahuja J. A study of gamma-glutamyltransferase in type 2 diabetes mellitus and its risk factors.Int J Clin Biochem Res. 2012;4:89-95.

Table 1: Comparison of Serum GGT levels between study groups and control groups.

\begin{tabular}{lccccc} 
Parameters & \multicolumn{2}{c}{ Study group } & \multicolumn{2}{c}{ Control group } & p-Value \\
& Mean & Standard Derivation & Mean & $\begin{array}{c}\text { Standard } \\
\text { Derivation }\end{array}$ & \\
\hline Serum GGT & 68.34 & 45.04 & 31.22 & 12.40 & $<0.00$ o $^{* *}$ \\
\hline
\end{tabular}

Table 2: Comparison of GGT levels between controlled cases and uncontrolled cases of Diabetes Mellitus.

\begin{tabular}{ccccccc} 
Serum GGT(IU/L) & \multicolumn{4}{c}{ HbAic (\%) } & \multicolumn{2}{c}{ Total } \\
& & $<6.5$ & $6.6-8.5$ & $8.6-10.5$ & $>10.5$ & \\
$<20$ & $\mathrm{~N}$ & 1 & 1 & 1 & 1 & 4 \\
\multirow{2}{*}{$21-52$} & $\%$ & $16.6 \%$ & $5.8 \%$ & $6.7 \%$ & $8.4 \%$ & $8.0 \%$ \\
& $\mathrm{~N}$ & 1 & 10 & 8 & 5 & 24 \\
$>52$ & $\%$ & $16.7 \%$ & $58.9 \%$ & $53.4 \%$ & $41.7 \%$ & $48.0 \%$ \\
& $\mathrm{~N}$ & 4 & 6 & 6 & 6 & 22 \\
\multirow{2}{*}{ Total } & $\%$ & $66.7 \%$ & 35.9 & $40.0 \%$ & $50.0 \%$ & $44.0 \%$ \\
& $\mathrm{~N}$ & 6 & 17 & 15 & 12 & 50 \\
\hline
\end{tabular}

Table 3: Correlation of Serum GGT with Plasma FBS and HbAic in the study group.

\begin{tabular}{llcc} 
& & Plasma FBS & HbAic \\
\multirow{3}{*}{ Serum GGT(IU/L) } & Pearson Correlation & -0.098 & -0.007 \\
& Sig. (2-tailed) & 0.498 & 0.961 \\
& $\mathrm{~N}$ & 50 & 50 \\
\hline
\end{tabular}

**. Correlation is significant at the o.o1 level (2-tailed). 